Scholarly Collaboration Across Time Zones

\author{
Kathy Lynch, University of the Sunshine Coast, Australia \\ Tel: +61 75456 5506, Fax: +61 754594727 \\ Kathy.Lynch@usc.edu.au \\ Aleksej Heinze, University of Salford, England \\ Tel: +44 161295 5024; Fax: +44 1612955999 \\ A.Heinze@salford.ac.uk \\ Eljse Scott, University of Cape Town, South Africa \\ Tel: +27 21650 4258, Fax: +27 216502280 \\ Elsje.Scott@uct.ac.za
}

Lynch, K., Heinze, A., \& Scott, E. (2009). Scholarly Collaboration Across Time Zones. In J. Salmons \& L. Wilson (Eds.), Handbook of Research on Electronic Collaboration and Organizational Synergy (pp. 237 - 249). London: Information Science Reference (an imprint of IGI Global). 


\section{Scholarly Collaboration Across Time Zones}

\section{ABSTRACT}

The barriers to global collaboration of yesteryear were, for example, country boundaries and time zones. Today however, in a world where communication is thriving on new technologies, these barriers have been overcome, not only by the technology itself, but also by the collaborators in a desire (and need) to extend knowledge, seize opportunities and build partnerships.

This chapter reports on one such collaboration: a case study where the focus is the writing of a scholarly article between authors from Australia, England and South Africa. The challenges of different time zones, academic calendars, and managing the collaboration are outlined in this chapter. Findings from the case study suggests that the key elements of success are related to the individuals and project management techniques, and not the technology per se. The constructivist learning theory as well as the e-Moderation model are supported by this work and thus extend their application to the academic writing process.

\section{BIOGRAPHICAL SKETCH}

Dr Kathy Lynch is an Associate Professor in ICT Research and Development, at the University of the Sunshine Coast, Queensland, Australia (previously of Monash University, Melbourne). Her current research interests encompass collaborative work, enabling and emerging technologies, HCI, usability, and IS/ICT education. She has a Doctor of Philosophy (Education), together with other qualifications in the disciplines of IT and Education. She is the Editor-in-Chief of the Interdisciplinary Journal of Information, Knowledge, and Management (IJIKM).

Aleksej Heinze is a Lecturer in the Salford Business School, University of Salford, England. His current research interests are concerned with the practice of blended e-learning in higher education and the general application of information technology for educational purposes. Additionally his interests include information security standards, search engine optimization and general software engineering. He is a member of the British Computer Society and the UK Higher Education Academy.

Elsje Scott is a Senior Lecturer in the Department of Information Systems, University of Cape Town, South Africa. Her main research interest is systems development group projects which include knowledge areas such as project management, people management and software engineering. Her specific focus areas are software testing, object-oriented programming concepts, general issues concerning the development of efficient computer systems in Information Systems, assessment strategies and software standards. 


\section{INTRODUCTION}

As an academic, how many times have you listened to a presenter, or read a paper, and thought to yourself that you would like to have a discussion with the presenter or author to develop a research project with them? How often has this actually happened? Have you ever considered why it has, or has not come to fruition?

This chapter reports on one such occasion where the research did eventuate. Lynch, Heinze and Scott were all presenters at the InSITE 2006 conference in Manchester, England. From informal discussions emerged a formal commitment to collaborate across land, sea and time to explore and share the approaches and challenges in the delivery of capstone or team projects in their information technology undergraduate degree programs at their respective universities.

This chapter presents the processes undertaken by the academics to write, edit and present a scholarly article. It exposes the issues, problems and challenges encountered during the collaboration, and concludes with several recommendations that could be used when considering collaborating in similar settings.

The chapter is organized in the following manner: First of all the background to the case study is outlined drawing on the literature on collaboration and information communication technologies, and the way these can be used to facilitate online collaboration. This section is followed by the case study description, which outlines the work undertaken and provides an analysis of the main issues encountered. The chapter then details the academic outcomes and benefits together with suggestions that others may wish to adopt in their online collaborations with academic peers. The key issues are then summarized in the conclusion section of the chapter.

\section{BACKGROUND}

The impact of information communication technology (ICT) in higher education has provoked a surge of publications examining online collaborative work. The dominant emphasis has been on students' learning through their engagement with technology, and in general, the application of technology for educational purposes and how these are best incorporated in the curriculum (Salmon, 2000; Collins, 2002). Pedagogy is understood to be the science of teaching, and it is the role of a teacher to be aware of the teaching process to facilitate student learning. Pedagogic research suggests that pedagogic paradigms are shifting from a behaviorist approach towards a constructivist stance (Cullen et al., 2002; Shepard, 2000), and that constructivism as it is applied today, is enabled by technologies that facilitate interaction, discourse and interactive writing (Lapadat, 2002). This enablement is exemplified by the work on Conversational Framework (Laurillard, 1993; 2002) and Conversational Theory (Heinze, Procter \& Scott, 2007; Scott, 2001a, 2001b). These publications highlight the development of a conversational dialogue between student and the teacher, and how different types of ICT can facilitate different aspects of the dialogue. The concepts of communities have been re-negotiated in the Internet era where virtual communities have become a popular paradigm (Bell, 2003).

\section{Information and communication technologies (ICTs)}

ICTs can be broadly categorized based on their speed of interaction (with the speed determined according to the time between when a sender sends a communication), to when 
the receiver receives the communication. An instant (or synchronous) communication is where participants exchange messages in real time; for example instant messenger dialogue, and the latter refers to communication which is not real time (or asynchronous); for example an email dialogue.

Web 2.0 and the Semantic Web are the latest generation of technological tools driven by the need for collaboration. Web 2.0 is based on the concept of simple online document editing which allows any user to voice their opinions (Rollett, et al, 2007). Web 2.0 examples include wikis, blogs and social networking sites such as YouTube ${ }^{\mathrm{TM}}$. Semantic Web is based on the vision of Tim Berners-Lee (Berners-Lee, et al, 2001), who wished to see the development of software agents capable of trawling the World Wide Web for information, and then sharing and integrating this information into collaborative work groups. Whilst it is difficult to predict the future of the technological developments, it is likely that Web 2.0 and the Semantic Web are two technologies which will be combined together for example in the form of semantic web-logs (Ankolekar, et al, 2007), which will be the basis for collaborative work.

\section{Collaborative work and ICTs}

Collaborative work refers to the interaction of two or more individuals on a certain task. With the aid of information communication technology this interaction can be via distance synchronously or asynchronously. Examples of such work usually include the effective harnessing of the benefits of Internet-enabled collaborative work by a number of industries despite the fact that individuals are geographically disbursed (Wellamn et al, 1996). The software development environment in particular lends itself to utilizing this method of collaboration (Herbsleb, Moitra \& Technol, 2001).

One of the benefits of using ICTs to enable collaboration is the reduced social presence, therefore allowing collaborators to focus on the task and ignore any other attributes which will be applicable in face-to-face communication. This can facilitate the members in being unrestrained, innovative and direct (Wellman et al, 1996), allowing the opportunity for shy participants to be on the same level as extraverts (Johnson, 2001). Asynchronous online communication is particularly good in enabling social and cognitive construction of meaning, which because of its nature is based around interactive writing (Lapadat, 2002).

Whilst some benefits emerged through the use of the online communication tools, these tools also raised some challenges such as misunderstandings due to reduced communication cues (Heinze and Procter 2006), and the perception of value for money:

"Yet many corporations have invested millions of dollars in top-of-the-line technology, only to be disappointed when there is no commensurate improvement in performance."

Benson-Armer and Hsieh (1997, pg 18).

One of the most acknowledged problems with collaborative work is the issue of withdrawal or attrition of members (Johnson, 2001). This is also an issue when the work is conducted within a virtual space. Furthermore, participation in a virtual team has other similar problems that are evident in face-to-face settings; these include group membership, organization, approach and timing aspects (Noël \& Robert, 2004). Although Web 2.0 and the Semantic Web are referred to as social networking technologies, elements such as "trust, openness, voluntariness and self-organization” (Rollett, et al, 2007, pg 87) are evident.

A number of scholars have shared their views on how to enable effective and efficient collaboration. In particular the e-Moderating model (Salmon, 2004) provides a pragmatic 
guide on how technological engagement is best facilitated by structuring the process into five stages. The stages are: Access and motivation, Online Socialization, Information Exchange, Knowledge construction and finally the Development stage. Despite its prescriptive nature (Lisewski \& Joyce, 2003) this model has a number of helpful suggestions for anyone embarking on online collaboration. The various stages of this model are supported by subsequent research, for example facilitation in respect of online communication mechanisms and technical support (Johnson, 2001).

The use of collaborative ICTs, in particular, social networking tools such as blogs, synchronous video/text tools such as Skype ${ }^{\mathrm{TM}}$ provide opportunities for interaction and dialogue between the authors that are separated by time and space. A warning for those who are involved in collaborating over time and space is not new, as highlighted by Dillon:

"The role of the technology surely is to support people and to this end designers should not try to control or manipulate collaboration but just concentrate on providing the most transparent media possible and let the naturally occurring process of group working take care of itself"

(Dillon, 1993, pg 85).

Another theme that supports the operation of collaborative work is to suggest the use of negotiated norms and structure (Wellman et al, 1996). Establishing norms or "online etiquette" is perceived as a useful stage to inform the participants and remind them of the limitations associated with online communication. Although consensus amongst all parties is desirable in an ideal world, this is not always possible (Bell \& Heinze, 2004). It is also difficult to prescribe the desired level of control within such online learning interaction. Rigidity might stiffen the development of a dialogue whereas too little structure might result in participants not focusing on the subject matter and emerging themselves in social interaction (Heinze \& Procter, 2006). However, it is acknowledged that online social interaction is an important part of enabling dialogue which in turn facilitates knowledge sharing (Zaitseva, Shalyor \& Whatley 2005; Heinze \& Procter 2006). Heinze \& Procter (2006) support the socialization stage of the e-Moderating model:

"Knowing each other eases the communication barriers and reduces the fear of posting messages into an open forum.” (Heinze \& Procter, 2006, pg 236)

The issue of knowing each other also increases the "credibility and trust" (BensonArmer \& Hsieh, 1997) which are important factors to those workers who collaborate with reduced face-to-face contact.

The next section outlines the case study, where its description is grounded in the collaborative writing process literature.

\section{CASE STUDY DESCRIPTION}

The case outlined in this chapter stemmed from the authors' involvement in the development and delivery of systems development group projects that are critical and an integral part of an undergraduate Information technology program.

The three authors met at a conference in June 2006 (InSITE 2006), where they challenged themselves to collaboratively write an account of the common highlights and different approaches used for the delivery of their capstone or team projects. The authors are academics from different universities, and geographically and temporally dispersed. 
Together with the academics' desire to share their knowledge and experiences, and the advent of digital communication technologies, the opportunity arose to collaborate through harnessing technology.

Academic writing in relation to a specific topic enhances authors' understanding of the subject matter (Shih, 1986). The academic peer-review process which is associated with the majority of books and journals engages the authors in a dialogue. This leads to one perception of scholarly writing as a conversation and has a number of stages (Huff, 1999). These stages are initialization, drafting and reviewing. Collaborative writing is a cyclical process, evolving from initial idea inception in the form of a rough plan, to drafting and revision stages until the authors feel that the documents are ready. The planning, drafting and revision are generally executed on various levels.

The given case study can be described using the conversation (Huff, 1999) and the eModeration (Salmon, 2004) models. In writing the scholarly paper the authors aligned - with modification, the writing process with the three stages of Huff's (1999) model for conversation. Huff's 'Reviewing stage' is referred to as the 'Revision stage', and an additional stage was added - the "Closing stage' due to the requirement to conduct a presentation of the paper at a conference. Elements of the five stages of Salmon's eModerating model (Salmon, 2004) are reflected in the stages of the collaboration process. This highlights the versatility of the model for peer collaboration and not only for facilitating the learning of students. Table 1 illustrates how Salmon's e-Moderating model (2004) further refines Huff's stages of communication and was mapped in this study.

The first stage of initialization or access and motivation was negotiated in a face-toface contact by the three authors during their participation in the InSITE 2006 conference. The initiation process was then extended to the online environment where email communication was used to focus this collaboration. The Huff drafting stages are broken down further into two sub-stages, that of drafting before the reviewers' comments and then subsequently, addressing the comments, bringing in yet another perspective on the collaboration and including the reviewers in the dialogue. The final stage was concerned with the presentation and submission of the manuscript which allowed the participants to reflect on the whole collaboration process.

Table 1: Matrix showing collaborative approach development - based on Salmon's eModeration model within Huff's conversation model.

\begin{tabular}{|l|l||l|}
\hline Huff (1999) & Salmon (2004) & Lynch, Heinze \& Scott approach to e-collaboration \\
\hline Initialization & Access and motivation & $\begin{array}{l}\text { Initialization: Access and motivation (face-to-face } \\
\text { meeting) }\end{array}$ \\
\hline Initialization & Online socialization & $\begin{array}{l}\text { Initialization: Information gathering (electronic } \\
\text { communication via email) }\end{array}$ \\
\hline Drafting & Information exchange & $\begin{array}{l}\text { Drafting: Knowledge construction (electronic } \\
\text { communication via email) }\end{array}$ \\
\hline Drafting & Knowledge construction & $\begin{array}{l}\text { Revision: (electronic communication via email and } \\
\text { Skype }\end{array}$ \\
\hline Reviewing & Development & $\begin{array}{l}\text { Closure: (face-to-face and Skype } \\
\text { TM }\end{array}$ \\
\hline
\end{tabular}

The linear description of this collaboration process which was aligned to Huff's and Salmon's models allows the identification of a holistic picture of this process. The following section will provide a more detailed description of each step: 


\section{The process}

Initialization stage:

Initialization for the project commenced at Lynch's presentation at the InSITE 2006 conference (Lynch, 2006). A number of academics were interested in the paper and associated topic (captone projects), for example Scott (2006). Lynch, Heinze and Scott all taught in information technology capstone or team projects; though the curriculum or delivery were different, there were similarities, and the benefit of further discussing the issues related with teaching this type of program were evident.

\section{Drafting stage:}

A conference was targeted, and a submission date identified. A paper was initiated from a skeleton of preliminary ideas. As the paper was about capstone or team projects, the initial structure was open in that each author took ownership of the section that described 'their' course. Once the initial ideas were conceptualized, the collaboration followed a cyclical process, evolving through stages of planning, drafting and revision. After each author constructed a first version of describing his/her individual course, it became evident that more structure was required. The paper was redesigned to include the same subheadings for each course. Within this new structure, the authors could elaborate and provide course specific information, including an account of the major challenges and benefits. The framework for the paper not only highlighted similarities across continents, but also reflected some unique approaches taken by each individual.

\section{Revision stage:}

As the complexity of the paper was known to increase, version control was initiated early on in the process. Figure 1 illustrates the chronological list of the drafting process. After the review process for the conference was completed, the paper was fast-tracked to a journal (Journal of Information Technology Education), and thus the paper required not only edits according to the conference reviewers, but also additional content and caliber in order to be suitable for a journal publication.

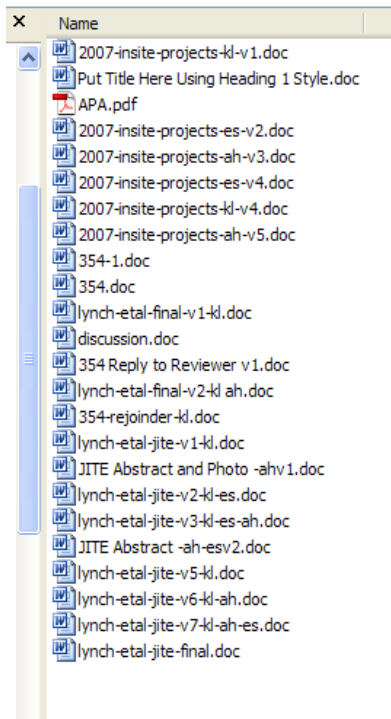

\begin{tabular}{rl|c}
\hline Size & Type & Date Modified \\
\hline 79 KB & Microsoft Word Doc... & $15 / 09 / 200608: 39$ \\
75 KB & Microsoft Word Doc... & $24 / 11 / 200608: 03$ \\
211 KB & Adobe Acrobat Doc... & $24 / 11 / 200608: 04$ \\
127 KB & Microsoft Word Doc... & $26 / 11 / 2006 ~ 20: 24$ \\
127 KB & Microsoft Word Doc... & $26 / 11 / 200620: 51$ \\
198 KB & Microsoft Word Doc... & $14 / 12 / 200610: 17$ \\
179 KB & Microsoft Word Doc... & $14 / 12 / 200610: 23$ \\
199 KB & Microsoft Word Doc... & $14 / 12 / 200610: 36$ \\
175 KB & Microsoft Word Doc... & $15 / 12 / 200608: 36$ \\
160 KB & Microsoft Word Doc... & $15 / 12 / 200608: 37$ \\
181 KB & Microsoft Word Doc... & $12 / 02 / 200719: 12$ \\
28 KB & Microsoft Word Doc... & $13 / 02 / 200712: 27$ \\
51 KB & Microsoft Word Doc... & $13 / 02 / 200714: 17$ \\
314 KB & Microsoft Word Doc... & $22 / 02 / 200710: 11$ \\
25 KB & Microsoft Word Doc... & $28 / 02 / 200708: 39$ \\
443 KB & Microsoft Word Doc... & $28 / 02 / 200708: 47$ \\
177 KB & Microsoft Word Doc... & $28 / 02 / 200714: 24$ \\
1,531 KB & Microsoft Word Doc... & $05 / 03 / 200715: 23$ \\
1,682 KB & Microsoft Word Doc... & $05 / 03 / 200715: 38$ \\
33 KB & Microsoft Word Doc... & $05 / 03 / 200715: 39$ \\
1,562 KB & Microsoft Word Doc... & $14 / 03 / 200707: 47$ \\
1,588 KB & Microsoft Word Doc... & $14 / 03 / 200708: 03$ \\
1,559 KB & Microsoft Word Doc... & $14 / 03 / 200710: 42$ \\
1,562 KB & Microsoft Word Doc... & $15 / 03 / 200708: 27$
\end{tabular}

Figure 1: Drafting process, and version control

A versioning control system and etiquette 'rules' (Wellman et al 1996) were implemented (see Figure 1); for example, '2007-insite-projects-kl-v1.doc' indicates that the paper was for the 2007 InSITE conference, with a short title of 'projects', it was last edited by ' $\mathrm{kl}$ ' signifying Kathy Lynch, and relates to 'v1' or version 1 of the document. There was only 
one person who could increase the version number - to prevent the issues of duplication, and this person was the lead author. The decision to change the version number was when a significant change was made- or all authors had contributed to the version.

Despite the challenges of passing the written token from one person to another, the authors managed to keep up the conversation by means of the collaborative/scholarly writing process as proposed by Huff (1999). In most cases all authors were copied in on emails, thus assisting individuals to keep track of the communication amongst the group members.

The 'Track Changes' functionality within Microsoft Word ${ }^{\mathrm{TM}}$ was extensively used (see Figure 2). This was accompanied by the use of 'Add Comment' within Microsoft Word $^{\mathrm{TM}}$, and to a lesser extent, the use of different colors was used to emphasize changes and points that required attention, or for clarity when many Track Changes were present.

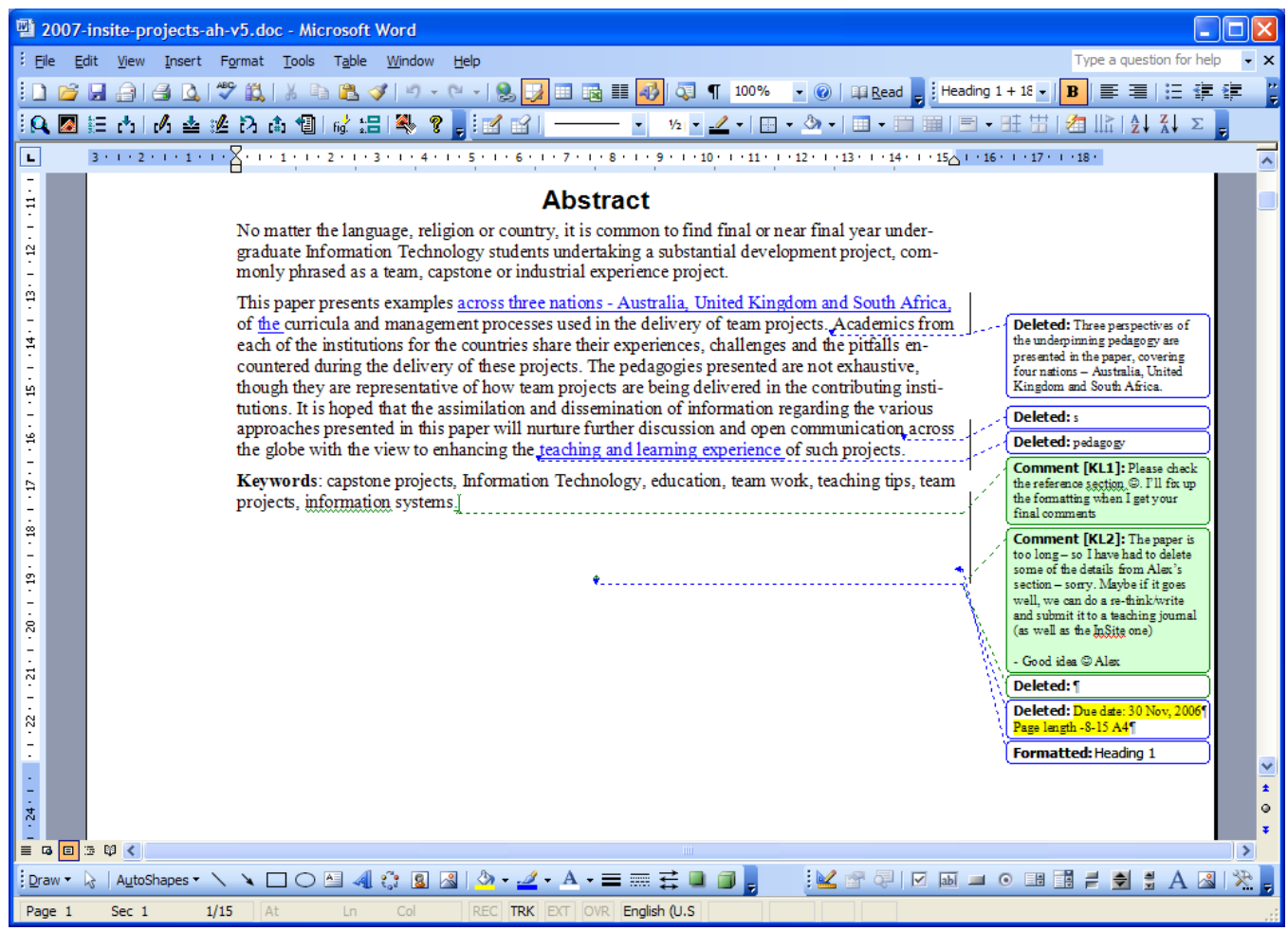

Figure 2. Use of Microsoft's Track Changes and Add Comment functions

During the paper revision stage Skype ${ }^{\mathrm{TM}}$ was used for 'virtual' face-to-face meetings. These meetings were infrequent during this stage, however the sessions were used to clarify complex sections of the paper, and to design the conference presentation (see Figure 3). 

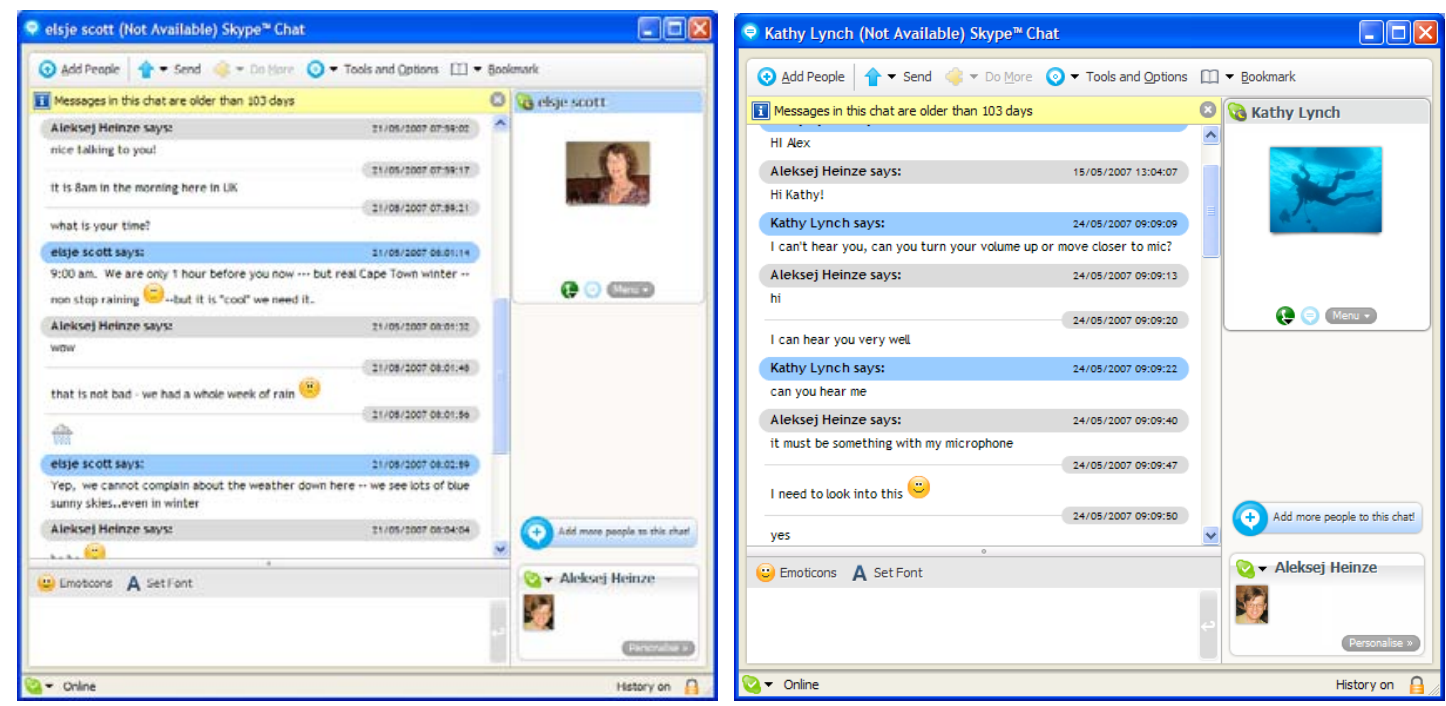

Figure 3. Skype ${ }^{\mathrm{TM}}$ meetings

The initial Skype ${ }^{\mathrm{TM}}$ session between the three authors was not particularly successful due to bandwidth limitations, hardware problems, and token passing between the participants. However, with practice, a few 'rules', and complimentary use of the 'text/chat' feature, these sessions were very favorability received, not only for the academic discussion, but for their socializing aspect.

\section{Closure stage:}

The final stage involved developing the presentation for the conference paper (Lynch, Heinze \& Scott, 2007) at the InSITE 2007 conference in Ljubljana, Slovenia. The presentation slides were designed and developed by the three authors using Skype ${ }^{\mathrm{TM}}$, email and Microsoft PowerPoint ${ }^{\mathrm{TM}}$, with Lynch taking the lead. The presentation format was the same for all three institutions, though their own personalities emerged, highlighting some of the differences between the countries. It was a disappointment to discover that the full team would not be participating in the physical face-to-face conference presentation; only Lynch and Heinze were able to attend the conference. Consequently, the conference organizers gave permission and support for the presenters to use Skype ${ }^{\mathrm{TM}}$, thus enabling Scott to be a 'virtual' presenter for the presentation. Although there were a few technical issues (lag time due to limited bandwidth), the authors felt that the presentation was a success.

Regardless of the differences between the academics and their institutions, one similarity was very evident,: the academics' commitment to both the scholarly community and to their students.

There were a number of lessons learned as a consequence of this collaboration. The following sections of this chapter will focus on the academic outcomes, challenges and tips in collaborative writing.

\section{ACADEMIC OUTCOMES}

Within the context of the collaboration detailed in this chapter, several positive learning experiences emerged from the collaboration, these were, professional development, and research opportunities. 


\section{Professional development}

The academics had first-hand experience with the challenges associated using ICTs in the development of a 'product'; something that they often force their students to do, though not necessarily having broad experience themselves. Added to this are the complexities of collaborating across time zones with implications of conflicting priorities, deadlines, language differences, and working with colleagues whom you knew very little about. Though this was challenging, it was a great opportunity to develop as an academic.

Furthermore, the opportunity to discuss, compare, share and learn from others who have similar challenges is something that should not be underestimated. The discussions that arose during the process generated a cross-cultural view on solutions to delivery issues, and were a bonus to the collaborative writing process. Subsequent discussions not associated directly with the capstone or team project issues, for example, the conundrum of the decline in IT student numbers together with the increase in demand for IT professionals, were welcomed as a global perspective is not always easy to gather or contribute to in a nonthreatening environment.

\section{Research opportunities}

The development of a research project can be related to the researcher's confidence in conducting research themselves, or being a valuable contributor to a research project. Both of these come with experience; this project has not only added to the authors' confidence in contributing to a research project, but confidence to act on ideas, and initiate research projects. Additionally, the development of future collaborative opportunities with the same team or their colleagues, are now a possibility; for example, investigating global systems development projects, joint student capstone/team projects or other student projects.

\section{CHALLENGES, TIPS AND RECOMMENDATIONS}

Writing an academic conference paper, planning a presentation and re-working a conference paper for a journal are not simple tasks for any academic. For the three academics, the geographical distance of 7, 000 to 20,000 kilometers, and a time difference of between one to nine hours, were not the only challenges: They each had different levels and fields of formal education, different native languages, involved in different undergraduate university programs, and differences between universities; such as, university calendars, courses (Information Systems, and Computing), course deliverables, and, operational differences (mixed program of first, second and third year students, to third year only students). These differences were overcome through a consultative and cooperative process. The following section outlines a number of recommendations or tips that could assist others who undertake collaborative writing over geographically and temporally dispersed circumstances.

Furthermore, these recommendations could easily be transposed to any collaborative project where the sharing of knowledge, learning and collaboration are at the foundations of the effort.

\section{Motivation}

All parties involved in collaboration, and in particular where there are temporal and spatial differences, need to be motivated to engage with each other. In the case reported in this chapter, the authors were all dealing with similar problems in their own institutions; each realizing that their problems were not unique to their course, students or institution. Each team member needs to be able to see the advantage of working with others, the benefits that will eventuate. In the case of this academic collaboration, each author could see that working 
with other like-minded academics would benefit the courses in their own institutions bringing new ways of addressing similar issues to the fore; a strong motivator.

Furthermore, all collaborators who are affected by the same problems are arguably "blind" because of their interpretive, and biased views. Motivation is related to priority, the time to work on a collaborative project needs to be allocated if the collaboration is to be productive and realized. Being able to keep a virtual collaboration a high priority is difficult. The authors found that one of the strengths of collaborating across time zones was that time became an advantage. A 24 hour effort could often be exploited because of the time differences, for example one author would send their draft at the end of their day and the other author would work on it whilst the first author was asleep.

\section{Milestones and deadlines}

The idea of meeting someone at a conference and perhaps ending up exchanging a couple of emails about some thoughts is a reasonable expectation. However, in order to learn more from the interaction, an academic paper writing process allowed channeling the energy and enthusiasm to a structured exchange of information between the three institutions. The deadline for submission was a great help to focus this work even further and the information exchange progressed to knowledge construction and development, therefore, underpinning the e-Moderating model of Salmon (2004).

\section{Curiosity}

How do people write papers in different countries? It was interesting to learn that last minute finishing was a problem not only suffered by the students but also by the academics in the three countries that collaborated. Collaborative writing also facilitated the constructivist social interaction to enrich each collaborator with new knowledge and broadened horizons. The curiosity of working closely with others; their writing style, language, thought processes, and knowledge, are all areas that add to ones academic curiosity and development.

\section{Leadership}

An experienced leader is required for any project, and the importance of their role cannot be underestimated. Being able to identify key areas and structure for a paper and playing a major role in ensuring the paper adheres to the necessary quality standards, keeping on track (though being flexible and accommodate members' schedules), is of paramount importance. The well regarded project management techniques of planning, scheduling and controlling are just as well suited to collaborating on an academic paper, as they are to working on an information system development project. Although the structure of the paper evolved, a plan for the paper structure was of great benefit to focus initial work and was then used to accommodate reviewers' comments.

\section{Team Spirit}

Team spirit is reflected in DuBrin's (2002) definition of a group as " $a$ collection of people who interact with one another, are working towards a common purpose, and perceive themselves to be a group". Team spirit cannot be forced, it emerges through trust and the worthiness of the cause and develops and deepens. The team spirit during this collaboration was high; respect, trust and friendships developed.

\section{Commitment}

Katzenbach and Smith (1993) define a team as a group that has a high degree of commitment from its members to achieving its goals and given objectives. In academic 
writing this commitment needs to be present at the onset of the project, and may need to be re-energized during times of heavy work pressures - which may be at different times for each contributor, and when milestones and deadline are determined.

Overall the constructivist notion of learning as a social process has been highlighted in this chapter. The paper writing process provided common problems and a focus to channel the collaborative enquiry which enriched the experience of the individuals on a number of levels.

\section{CONCLUSIONS}

This chapter outlined the developments of a successful scholarly collaboration across time and space borders where ICT supported and enhanced the collaboration. The success can be measured in terms of accepted deliverables to conference and journal publications, hence contributing to knowledge of the academic community. The collaboration is an example and supports Dillon's view (1993) that technology is there to support collaboration but success is entirely dependent on the individuals taking part in the process. It was shown through this case, that using simple tools such as a word processor, email and instant chat facilities was sufficient to support this process. More and more collaboration is taking place and will continue, gain momentum, and will happen across different times and spaces. The onset of virtual spaces (for example Second Life), and the explosion of social networking tools (for example, Blogs, and Wikis), can only advance collaboration using electronic means. There are a number of other tools which could be considered for future collaboration, however, the technology alone will not make the collaboration a success. The main themes that contribute to the success of this case study are related to the individuals and their motivation, curiosity, team spirit and commitment, project management techniques such as milestones and deadlines, and good leadership.

It is not only important that students are being prepared to collaborate across time and spatial boundaries, it is also time for academics to take advantage of new and emerging technologies to advance their research, teaching and professional development. The case presented here demonstrates the constructivist belief regarding the social learning experience and learning from each other. This is in line with the developments in the Conversational Theory (Heinze, Procter \& Scott, 2007), which underpins the need for dialogue to facilitate learning. In our case the dialogue was based on a topic of common interest and had the purpose of a joint publication. The experience provided a development means for academics which highlights how a simple paper writing process can facilitate learning. Because the paper was to be presented as a coherent document, the meanings amongst authors had to be negotiated and this process allowed the shaping of individual's beliefs and understanding.

The case study suggests that the stages of collaborative writing as proposed by Huff (1999) can be further subdivided into the stages proposed by Salmon (2004), have been furthered refined as stages for e-collaboration by Lynch, Heinze and Scott as Initialization, Drafting, Revision and Closure. This increase of stages justifies and takes into account the academic nature of collaborations.

At conferences, or other face-to-face meetings, time can be used for the negotiation of the specific topic, followed by the electronic exchange to facilitate the writing process, providing an audit trail and self documentation of communication and the ideas development. For example, in the case presented here, no meeting minutes or agendas were necessary in this communication since all interaction was self-documented. The final stage of conference presentation was also conducted in a face-to-face environment - albeit virtual, which allowed the participants to reflect and write yet another paper. 
The motivation for the collaboration presented in this chapter was based on an enthusiastic desire (and need) to share knowledge and experiences. Despite a rapidly changing environment (Gupta \& Wachter, 1998; Novitski 2001), educational institutions are faced with the challenge to constantly adapt curricula in an attempt to maintain an effective balance between technical expertise, up-to-date business knowledge and collaborative work skills (Lynch \& Fisher, 2007) in their programs. The opportunity to share expertise from across the globe to enhance what/how we teach and learn, is common in dissemination, though far less common in the collaboration or construction of knowledge. It is the hope of the authors that their experience will inspire other academics to take advantage of opportunities that arise regardless of where the possible collaborators may be located. 


\section{REFERENCES}

Ankolekar, A., Krötzsch, M., Tran, T. and Vrandecic, D. (2007). ” The two cultures: mashing up web 2.0 and the semantic web” International World Wide Web Conference, Proceedings of the 16th international conference on World Wide Web, Banff, Alberta, Canada, 825 - 834 Available online on 09 September 2007:

http://doi.acm.org/10.1145/1242572.1242684

Bell, F. (2003) "Learning Communities - Reality or Feelgood Factor” Education in a Changing Environment 17th-18th September 2003, Conference Proceedings, University of Salford. Salford, UK. Available online on 09 September 2007: www.ece.salford.ac.uk/proceedings/papers/fb_03.rtf

Bell, F. and A. Heinze (2004). "With regard to respect: a framework for governance of educational virtual communities." International Journal Web Based Communities 1(1): 19- 34. Available online on 9th September 2007: http://openurl.ingenta.com/content?genre=article\&issn=14778394\&volume $=1$ \&issue $=1 \&$ spage $=19$ \&epage $=34$

Benson-Armer, R. and Hsieh, T. (1997). “Teamwork across time and space” The McKinsey Quarterly, No. 4, 18-27. Available online on 09 September 2007:

http://www.questia.com/googleScholar.qst?docId=5001525234

Berners-Lee, T., J. Hendler, Lassila. O.. (2001). "The Semantic Web: A new form of Web content that is meaningful to computers will unleash a revolution of new possibilities," Scientific American: Available online on 17 December 2007: http://www.sciam.com/article.cfm?id=the-semantic-web

Collins, B. (2002). Information Technologies for Education and Training. Heidelberg, Springer Verlag - Berlin.

Cullen, J., K. Hadjivassiliou, Hamilton, E., Kelleher, J., Sommerlad, E. And Stern, E (2002). Review of current pedagogic research and practice in the fields of post-compulsory education and lifelong learning. London, The Tavistock Institute.

Dillon, A. (1993). "How collaborative is collaborative writing?: an analysis of the production of the technical reports”. In M. Sharples, (ed) Computer Supported Collaborated Writing, London, Springer Verlag, 6986. Available online on 09 September 2007: http://dlist.sir.arizona.edu/1194/01/Ad1993.pdf

DuBrin, A.J. (2002). “1-15”. In Fundamentals of Organizational Behavior, eds. Szilagyi, J., South-Western College Publishing, United States of America, 1-372.

Gupta., J. N. G \& Wachter R.M. (1998). A Capstone Course in the Information systems Curriculum. International Journal of Information Management. Volume 18, Number 6, December 1998 , pp. 427-441.

Heinze, A. and C. Procter (2006). "Online Communication and Information Technology Education." Journal of Information Technology Education 5: 235-249. Available online on 9th September 2007:

http://jite.org/documents/Vol5/v5p235-249Heinze156.pdf

Heinze, A., C. Procter and Scott B. (2007). "Use of Conversation Theory to underpin Blended Learning." International Journal of Teaching and Case Studies 1(1 \& 2): 108-120. 
Herbsleb, J.D., Moitra, D. and Technol. L., (2001). “Global software development” IEEE Software, 18, 2, 16-20

Huff AS (1999). Writing for Scholarly Publication, Sage Publications, London Available online on 09 September 2007:

http://books.google.com/books?pg=PT1\&dq=ISBN+0761918051\&ei=FkTkRqagIajA7gKfzc2FDQ\&sig=hLaelZ sGk49DLsIT5Yrl9wqx5nE\&id=w8GoYutoYFQC

InSITE (2006) Informing Science + Information Technology Education Conference, 2006. http://proceedings.informingscience.org/InSITE2006/insite2006.htm

Katzenbach, J.R. \& Smith, D.K. (1993). The discipline of teams, Harvard Business Review, 71 (2), 111-120.

Johnson, C. M. (2001) “A survey of current research on online communities of practice” Internet and Higher Education 4, 45-60 Available online on 09 September 2007:

http://www.sc-eco.univnantes.fr/ tvallee/memoire/pratique/A\%20survey\%20of\%20current\%20research\%20on\%20online\%20communi ties\%20of\%20practice.pdf

Lapadat, J. C. (2002) “Written interaction: A key component in online learning” Journal of Computer-Mediated Communication. 7, 4. Available online on 09 September 2007: http://jcmc.indiana.edu/vol7/issue4/lapadat.html

Laurillard, D. (1993). Rethinking university teaching: A framework for the effective use of educational technology. London, Routledge/Falmer.

Laurillard, D. (2002). Rethinking university teaching: A framework for the effective use of educational technology. London, Routledge/Falmer.

Lisewski, B. and P. Joyce (2003). "Examining the five stage e-moderating model: designed and emergent practice in the learning technology profession." Alt-J 11,1,55-66.

Lynch, K., (2006). “Readiness to communicate in a digital world”. In Issues in Informing Science and Information Technology Vol 3, pp 289-298. Available online on 9th September 2007: http://informingscience.org/proceedings/InSITE2006/IISITLynch115.pdf

Lynch, K., Heinze, A and Scott, E. (2007). "Information technology team projects in higher education: An international viewpoint." Journal of Information Technology Education 6: 181-198. Available online on 9th September 2007: http://jite.org/documents/Vol6/JITEv6p181-198Lynch354.pdf

Lynch, K \& Fisher, J. (2007) "Tomorrow's workforce today: What is required by IS graduates to work in a collaborative Information Systems workplace?” Information Systems and Technology Education: From the University to the Workplace. Eds. Lowry \& Turner . Idea Publishing

Moore, R. C. (2005 - pending). The Capstone Course. In Christ, William G. (ed.) Assessing media education: A resource for educators and administrators. Hillsdale, NJ: Erlbaum. Retrieved November 20, 2006 from http://users.etown.edu/m/moorerc/capstone.html

Noël, S. and Robert, J.M. (2004). "Empirical Study on Collaborative Writing: What Do Co-authors Do, Use, and Like?” Computer Supported Cooperative Work (CSCW), Springer Netherlands, 13, 1, 63-89 
Available online on 09 September 2007: http:/www.springerlink.com/content/p0867n5746730504/

Rollett, H., Lux,M., Strohmaier, M., Dosinger, G., Tochtermann, K., (2007). ” The Web 2.0 way of learning with technologies” International Journal of Learning Technology. 3, 1, 87 - 107

Available online on 09 September 2007: http://inderscience.metapress.com/link.asp?id=fx5fuw48r3x8jcc7

Salmon, G. (2000). "Computer Mediated Conferencing for Management Learning at the Open University." Management Learning 31(4): 491 - 502.

Salmon, G. (2004). E-Moderating: The key to Teaching and Learning online. London, RoutledgeFalmer.

Scott, B. (2001a). "Conversation Theory: A Constructivist, Dialogical Approach to Educational Technology." Cybernetics and Human Knowing 8(4): 25 - 46.

Scott, B. (2001b). "Gordon Pask’s Conversation Theory: A Domain Independent Constructivist Model of Human Knowing." Foundations of Science, special issue on "The Impact of Radical Constructivism on Science" 6(4): 343 - 360.

Scott, E., and Pollack, M “Effectiveness of Self-selected Teams: A Systems Development Project Experience” In Issues in Informing Science and Information Technology Vol 3, pp 601-618. Available online on 9th September 2007: http://informingscience.org/proceedings/InSITE2006/IISITScot217.pdf

Shepard, L. A. (2000). "The Role of Assessment in a Learning Culture," Educational Researcher, 29,7, 4-14.

Shih, M. (1986). “Content-Based Approaches to Teaching Academic Writing” TESOL Quarterly, 20, 4, 617648, Available online on 09 September 2007:

http://links.jstor.org/sici?sici=0039-8322\%28198612\%2920\%3A4\%3C617\%3ACATTAW\%3E2.0.CO\%3B2K\&size=LARGE\&origin=JSTOR-enlargePage

Wellman, B., Salaff, J., Dimitrova, D., Garton, L., Gulia, M. and Haythornthwaite, C (1996). “Computer Networks As Social Networks: Collaborative Work, Telework, and Virtual Community.” Annual Review of Sociology, 22, 213-238. Available online on 9th September 2007: http://www.chass.utoronto.ca/ wellman/publications/computernetworks/computernetworks2.pdf

Zaitseva, E., Shaylor, J. and Whatley, J., (2005). Collaboration Across Border: Benefits and Pitfalls of an International Collaborative Project. Education in a Changing Environment Conference, University of Salford, Salford, UK Available online on 09 September 2007: http://www.ece.salford.ac.uk/proceedings/papers/ez_04.rtf.

\section{Key Terms and Their Definitions}

Asynchronous communication - and the latter refers to communication which is not real time (or asynchronous); for example an email dialogue.

Capstone course (or Team Projects, or Industry Project, or Industry Experience Project)- The capstone course of any university degree is the integration of all learning gained from courses in the major with other learning from all supplementary courses undertaken to attain the degree (Moore, 2005 ). "A Capstone course forms the culmination of many learning experiences students encounter during their academic careers” (Lynch, Heinze, \& Scott, 2007). 
Collaborative work - work that involves more than one individuals working towards a common goal.

Constructivism - pedagogic theory that builds on the ideas of Jean Piaget (18961980), John Dewey (1859-1952) and Lev Semenovich Vygotsky (1896-1934). This pedagogy emphasis that learning is a social activity and therefore should be facilitated via a continuous interaction of learner with teacher. The emphasis of learning is to learn problem solving skills in relation to real life (Shepard, 2000).

Information Communication Technology (ICT) - a broad term encompassing the use of software and hardware to facilitate manipulation and processing of information. Examples of ICT include laptop computer and the Internet.

Pedagogy - is understood to be the science of teaching, concerned with the method used to facilitate student learning.

Synchronous communication - an instant (or synchronous) communication is where participants exchange messages in real time; for example instant messenger dialogue via Skype ${ }^{\mathrm{TM}}$

\section{Index words}

Capstone projects

Team projects

Collaboration

Time zones

Scholarly collaboration

Project management

Trust

Motivation

Team spirit

e-Moderation

e-Collaboration

Information technology undergraduate programmes

ICT

Information and communication technology

Constructivism

Process writing

Leadership

Commitment 